\title{
A Preliminary Study on the Influence of Highway Design Factors on Traffic Safety
}

\author{
Kai Long ${ }^{1, a}$ \\ ${ }^{1}$ Shandong CHECSC Highway Design Consulting Co.Ltd. DongYing 257091, China \\ apigsky2002@126.com
}

Keywords: highway design factor; traffic safety; influence; preliminary study

Abstract. With quicker construction of urban roads, more and more highway projects are put into construction. Highway design determines traffic safety. In the actual highway design, corresponding design factors have a huge impact on traffic safety. Therefore, to ensure traffic safety, we need to analyze highway design factors and rule out factors affecting traffic safety.

\section{Introduction}

According to surveys, there are many factors affecting traffic safety on roads. The occurrences of most traffic accidents are related to incomplete highway design factors. Under non-ideal urban traffic, to guarantee people's travel safety, we focus on safety factors in highway design. In view of requirements of traffic construction, feasible countermeasures are raised. Through the improvement of traffic quality, traffic safety is promoted.

1.The Influence of Highway Design Factors on Traffic Safety

The influence of highway sight distance design. The rationality of highway sight distance design has a significant impact on driving safety. Conventional sight distance design is mainly divided into planar sight distance and profile sight distance. In a good sight distance design, drivers need to fully adapt to the current driving environment, to respond to all kinds of driving conditions. In current sight distance designs, sight distance designs are improved through the designs of stopping, passing and meeting sight distance. However, due to height difference between vehicles and height difference between drivers, highway sight distance design is very complex. If a sight distance design is irrational, driving safety will be seriously affected. A drawing of highway sight distance design is shown in the figure below.

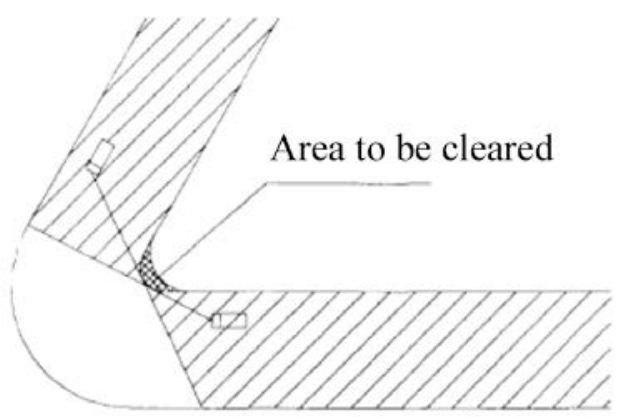

Fig. 1 Highway Sight Distance Design

Tab. 1 The Relationship between Sight Distance and Traffic Safety

\begin{tabular}{ll}
\hline Sight Distance (m) & $\begin{array}{l}\text { Accident Rate } \\
\text { (per million kms) }\end{array}$ \\
\hline Below 240 & 1.5 \\
$240-450$ & 1.2 \\
$450-750$ & 0.8 \\
Above 750 & 0.7 \\
\hline
\end{tabular}


2. The influence of highway plane linetype design. An improper highway plane linetype design will cause a severe impact on traffic safety. Such plane designs greatly interfere with driver's vision, psychology and driving schemes, etc. Plane linetype designs deviate from the reality on roads and have a direct impact on driver's driving, for example, unsteady driving speed. Many accidents thereby occur and plant in it the seed of safety hazards.

3. The influence of grade crossing design. Grade crossing design can effectively alleviate chaos in road traffic. This kind of design doesn't set open channel barriers, but plan routes on the road surface. In such a road design, drivers can't find tracks of lanes. When there are many vehicles, drivers may cut in or don't know which lane to choose. In crossing space, it may result in lower utilization rate of roads and frequent traffic accidents.

\section{Highway Design Optimization Schemes}

1. The improvement of highway sight distance design . In the improvement of highway sight distance design, in an actual highway environment, we need to do the following on a case-by-case basis: 1) sight distance design and time consideration. Generally, in a secondary highway design, a standard passing section must be set every 3 minutes. In a two-lane highway sight distance design, we need to arrange sight distance, in combination with the actual conditions and guarantee the rationality of sight distance design. 2) On the basis of traffic safety, it is required that highway sight distance should conform to requirements of driving clearance. 3) In sight distance design, we need to consider objects placed on roadsides, such as designs of flower beds, slopes and artificial structures, etc. Traffic signs and corresponding sections are designed and analyzed emphatically.

Tab. 2 Stopping Sight Distance for All Levels of Highways

Note: $\mathrm{PH}=$ Plain hill; $\mathrm{MR}=$ Mountain ridge.

\begin{tabular}{|c|c|c|c|c|c|c|c|c|c|c|c|c|c|c|}
\hline \multirow[t]{2}{*}{ Class } & \multicolumn{8}{|c|}{ Motorway } & \multicolumn{6}{|c|}{ General Highway } \\
\hline & & \multicolumn{3}{|c|}{ Expressway } & \multicolumn{2}{|l|}{$\mathrm{I}$} & \multicolumn{2}{|l|}{ II } & \multicolumn{2}{|l|}{ II } & \multicolumn{2}{|c|}{ III } & \multicolumn{2}{|c|}{ IV } \\
\hline Terrain & $\mathrm{PH}$ & Mountain & Rid & & $\mathrm{PH}$ & MR & $\mathrm{PH}$ & MR & $\mathrm{PH}$ & MR & $\mathrm{PH}$ & MR & PH & MR \\
\hline $\begin{array}{l}\text { Stopping } \\
\text { Sight }\end{array}$ & 210 & 160 & 110 & 75 & 160 & 75 & 110 & 40 & 110 & 40 & 75 & 30 & 40 & 20 \\
\hline $\begin{array}{l}\text { Distance } \\
\text { (m) }\end{array}$ & & & & & & & & & & & & & & \\
\hline
\end{tabular}

2. The improvement of highway plane linetype design. To eliminate the impact of plane linetype design on traffic safety, in plane linetype design, we need to fully consider drivers' psychology and visual habits. For example, designers should strictly control the length of straight sections, to guarantee speed on straight sections and vehicle throughput. On the design of curved sections, it is required that curve radius should be greater than the minimum radius. The curve radius of circles should be within $1 \mathrm{~km}$. In the transformation of terrains and sections, it is necessary to apply curve transition technology, to avoid traffic accidents caused by too high speed in curved sections. Meanwhile, in plane linetype design, we need to analyze traffic environments and realize the economy and rationality of environmental construction.

Tab. 3 The Relationship between Curvature and Traffic Accidents

\begin{tabular}{lllllll}
\hline Curvature & $0-1.9$ & $2-3.9$ & $4-4.9$ & $6-9.9$ & $10-14.9$ & $>15$ \\
\hline $\begin{array}{l}\text { Accident rate } \\
\text { (per million }\end{array}$ & 1.62 & 1.86 & 2.17 & 2.36 & 8.45 & 9.26 \\
kms) & & & & & & \\
\hline
\end{tabular}

3. The improvement of grade crossing design. To improve interferences resulting from highway grade crossing design, we need to adopt an improvement scheme for grade crossing design. 1) In grade crossing design, we should reduce conflicts between traffic flows as far as possible and reduce the area of conflict zone. 2) In crossing section design, we need to begin with sight distance guidance and avoid obstacles in junctions. 3) The space between grade crossings in primary and secondary highways should be adjusted as appropriate. 


\section{Conclusion}

To sum up, in traffic design, the designs of highway sight distance, plane and grade crossing will have a direct impact on traffic safety. To improve traffic safety, it is necessary to optimize the above aspects and improve highway safety realistically.

\section{References}

[1] Hassan, A. Halim. Design considerations for combined highway alignments[J]. Journal of Transportation Engineering, 1997, 123(1):60-68.

[2] Hulbert S. Effects of driver fatigue : In T.W. Forbes (Ed.), Human Factors in Highway Traffic Safety Research, Wiley-Interscience, New York, N.Y. USA 1972. Abstr in Psychological Abstracts[J]. Applied Ergonomics, 1974, 5(3):171-171.

[3] Benedetto A, Benedetto C, Blasiis M R D. A new effective approach to accidents prediction to improve roads' design and rehabilitation[J]. Advances in Transportation Studies, 2004, 4(4):5-32. 